\title{
THE PHOSPHOMOLYBDATE ESTIMATION OF PHOSPHORIC ACID IN SOILS.
}

\author{
By S. J. M. AULD, D.Sc. (Lond.), Pr.D., F.I.C.
}

(Read at the Meeting, March 6, 1912.)

THE necessity of estimating very small quantities of phosphoric acid during the chemical analysis of soils has lead to the suggestion of many methods for the direct utilisation of the bulky phosphomolybdate precipitate, instead of finally precipitating its ammoniacal solution with magnesia mixture.

The difficulties attending these methods are concerned chiefly with the variation in composition of the yellow ammonium phosphomolybdate precipitate, the constitution of which has been the subject of much investigation. Under standard methods of precipitation, however, any variation in composition is practically confined to the amount of ammonia in combination and to the quantity of water of crystallisation; this, of course, apart from the possible co-precipitation of molybdic acid, admixture with other ammonium salts or incomplete separation (in soil analysis) from silica, etc. The ratio of $\mathrm{P}_{2} \mathrm{O}_{5}: \mathrm{MoO}_{3}$ was originally stated by Debray and others to be $1: 20$, but was definitely shown by Finkener (Ber., 1878, 11, 1638) and Gibbs (Amer. Chem. J., 1882, 3, 317) to be $\mathrm{P}_{2} \mathrm{O}_{5}: \mathrm{MoO}_{3}=1: 24$. This has been confirmed more recently by Levi and Spelta (Gazz. Chim. Ital., 1903, 33, 207). Gibbs gives the formula of the yellow precipitate as

$$
\left(\mathrm{NH}_{4}\right)_{3} \mathrm{PO}_{4} \cdot 12 \mathrm{MoO}_{3}+\left(\mathrm{NH}_{4}\right)_{2} \mathrm{HPO}_{4} \cdot 12 \mathrm{MoO}_{3}+8 \mathrm{H}_{2} \mathrm{O} \text {; }
$$

whilst Finkener describes the precipitate, washed with ammonium nitrate solution and carefully heated in a crucible until the ammonium nitrate is volatilised, as

$$
(9-x)\left(\mathrm{NH}_{4}\right)_{2} \mathrm{O} \cdot x \mathrm{H}_{2} \mathrm{O} \cdot 3 \mathrm{P}_{2} \mathrm{O}_{5} \cdot 72 \mathrm{MoO}_{3} \text {, }
$$

where $x$ generally equals 1 . Carnot (Bull. Soc. Chim. 1893, 9, 343) regards the reprecipitated compound as

$$
3\left(\mathrm{NH}_{4}\right)_{2} \mathrm{O} \cdot \mathrm{P}_{2} \mathrm{O}_{5} \cdot 24 \mathrm{MoO}_{3} \cdot 3 \mathrm{H}_{2} \mathrm{O}
$$

and Hundeshagen (Zeit. f. Anal. Chem., 1889, 28, 141) states that the precipitate dried at $130^{\circ} \mathrm{C}$. is always

$$
\left(\mathrm{NH}_{4}\right)_{3} \mathrm{PO}_{4} \cdot 12 \mathrm{MoO}_{3} \text {, }
$$

independent of the content of mineral acids, phosphoric and molybdic acids, or ammonium salts. The ratio $\mathrm{NH}_{4}: \mathrm{P}_{2} \mathrm{O}_{5}$ is thus variously given as $5: 1,16: 3$, and 6:1. This may possibly be due to the fact, shown by Levi and Spelta (loc. cit.) that phosphomolybdic acid contains twenty-seven replaceable hydrogen atoms, five of which behave differently from the remaining twenty-two. The estimation of phosphoric acid by Carnot's method (loc. cit.), by weighing the reprecipitated compound after drying at $100^{\circ} \mathrm{C}$., which is still extensively used and recommended in certain textbooks, should therefore be rejected on the grounds of insufficient evidence of composition; besides which, the coefficient recommended by him-viz., 
0.0373 -is calculated on the fully hydrated precipitate of the formula given above. On the other hand, the factor 0.043 recommended by the Committee of the Association of Official Agricultural Chemists of the United States has been recognised as inaccurate ( $c f$. Wiley's “Agricultural Analysis, i. 423). To test the possible removal of water of hydration during drying, and the composition of the residual precipitate, an extended series of analyses by the Carnot method were carried out, using standard solutions of purified sodium phosphate to check the results, which were also controlled by dissolving the precipitates in ammonia solution and precipitating with magnesia mixture. Previous to drying, the precipitates were thoroughly washed with a 1 per cent solution of nitric acid.

TABLE I.

\begin{tabular}{|c|c|c|c|c|c|c|c|}
\hline & \multirow{2}{*}{ Series. } & \multirow{2}{*}{$\begin{array}{l}\text { Volume of } \\
\frac{\mathrm{N} \mathrm{Na}_{2} \mathrm{HPO}_{4}}{5} \\
\text { Solution. }\end{array}$} & \multirow{2}{*}{$\begin{array}{l}\text { Weight of } \\
\mathrm{P}_{2} \mathrm{O}_{5} \text {. }\end{array}$} & \multicolumn{2}{|c|}{$\begin{array}{l}\text { Precipitate dried at } \\
100^{\circ} \mathrm{C} .\end{array}$} & \multicolumn{2}{|c|}{$\begin{array}{l}\text { Precipitate dried at } \\
105^{\circ} \text { to } 110^{\circ} \mathrm{C} .\end{array}$} \\
\hline & & & & $\begin{array}{l}\text { A veragre } \\
\text { Weight. }\end{array}$ & Factor. & $\begin{array}{l}\text { Average } \\
\text { Weight. }\end{array}$ & Factor. \\
\hline $\begin{array}{l}1 \\
2 \\
3 \\
4\end{array}$ & $\begin{array}{ll}\ldots & \ldots \\
\ldots & \ldots \\
\ldots & \ldots \\
\ldots & \ldots\end{array}$ & $\begin{array}{r}\text { C.C. } \\
20 \\
15 \\
10 \\
5\end{array}$ & $\begin{array}{c}\text { Grms. } \\
0.0946 \\
0.0710 \\
0.0473 \\
0.0236\end{array}$ & $\begin{array}{c}\text { Grms. } \\
2.5165 \\
1.8761 \\
1.2671 \\
0.6300\end{array}$ & $\begin{array}{l}0.0376 \\
0.0378 \\
0.0375 \\
0.0376\end{array}$ & $\begin{array}{c}\text { Grms. } \\
2 \cdot 5045 \\
1 \cdot 8732 \\
1 \cdot 2443 \\
0 \cdot 6185\end{array}$ & $\begin{array}{l}0.0378 \\
0.0381 \\
0.0381 \\
0.0383\end{array}$ \\
\hline
\end{tabular}

Although carried out with care, a number of the estimations gave only approximate results, and these were not included in the above table. The method was certainly not completely satisfactory, and if used should probably be calculated from the coefficient 0.0378 , the theoretical value for the anbydrous salt. This, however, probably does not represent the true state of affairs, and it will be noticed that heating for some time at $105^{\circ}$ to $110^{\circ} \mathrm{C}$. gives a residue containing a percentage of phosphoric acid incompatible with Hundeshagen's asserted stability of the ammonium salt, assuming that his simple formula correctly represents its composition. This tends to confirm the statement of Dehérain ("Chim. Agricole," p. 449) that decomposition may ensue if the yellow precipitate is heated above $90^{\circ} \mathrm{C} . \mathrm{He}$ recommends the factor 0.0376 .

It was chiefly, however, for the purpose of examining the more generally adopted procedure of gravimetrically estimating the $\mathrm{P}_{2} \mathrm{O}_{5}$ in soils that this work was started. The operation, first suggested by Hehner (ANALYst, 1879, 4.23), consists of dissolving the ammonium phosphomolybdate precipitate in dilute ammonia, evaporating the ammoniacal solution, and weighing the residue after drying or gentle ignition. The factors employed for calculating the percentage of phosphoric acid vary somewhat according to different authors and works of reference, but, from their order of magnitude, apparently frequently depend on an assumed stability of the combined ammonia on heating at moderate temperatures : 


\begin{tabular}{|c|c|c|}
\hline Mode of Treatment. & Factor. & Reference. \\
\hline $\begin{array}{l}\text { Heat gently to volatilise the am- } \\
\text { monium nitrate } \ldots . . . \\
\text { Ignite gently over an Argand burner } \\
\text { Repeated evaporation to dryness } \\
\text { with small quantities of water } \ldots \\
\text { Heat to dark blue colour ... }\end{array}$ & $\begin{array}{l}0.0374 \\
0.0379 \\
\\
0.0350 \\
0.0396\end{array}$ & $\begin{array}{l}\text { Finkener (loc. cit.). } \\
\text { Hall ("The Soil," p. 146). } \\
\text { Hehner (loc. cit., p. 27). } \\
\text { Wood ("Pract. Agric. Chem.," p. 17). }\end{array}$ \\
\hline
\end{tabular}

The difference in the factors becomes of importance when one is forced to estimate very small quantities of $\mathrm{P}_{2} \mathrm{O}_{5}$, as, for example, in the estimation of available or " citric soluble" phosphoric acid in soil. In this case there is difficulty in increasing the amount of material used, and the weight of the final residue may not amount to more than 0.3 to $0.4 \mathrm{grm}$. During the heating, the residues generally take on a more or less blue colour-sometimes to a very considerable extent-and this cannot be controlled to any particular stage coincident with the complete removal of the extraneous ammonium salts. Hehner avoided this by washing the precipitate with dilute alcohol, dissolving in ammonia, and weighing the residue after repeated evaporation to dryness with small quantities of water.

The formation of the blue colour generally obtained would also indicate a partial decomposition of the phosphomolybdate, and suggest prima facie that the residue should be obtained either wholly yellow or wholly blue. That one is not so likely to obtain a uniform product at all by dissolution of the yellow precipitate in ammonia may be gathered from a consideration of the reactions involved.

According to Levi and Spelta (loc. cit.), ammonia resolves ammonium phosphomolybdate into ammonium phosphate and ammonium molybdate. Certainly, repeated evaporation of the ammoniacal solution with water gives acid molybdate and ammonium phosphate. But the reaction is probably not quite so simple as might be expressed by the equation

$$
\begin{gathered}
x\left(\mathrm{NH}_{4}\right)_{2} \mathrm{O} \cdot \mathrm{P}_{2} \mathrm{O}_{5} \cdot 24 \mathrm{MoO}_{3}+2(27-x) \mathrm{NH}_{4} \mathrm{OH}=24\left(\mathrm{NH}_{4}\right)_{2} \mathrm{O} \cdot \mathrm{MoO}_{3}+ \\
2\left(\mathrm{NH}_{4}\right)_{3} \mathrm{PO}_{4}+(27-x) \mathrm{H}_{2} \mathrm{O}
\end{gathered}
$$

and may, at any rate partially, involve the formation of ammonium phosphopentamolybdate :

$$
\begin{gathered}
x\left(\mathrm{NH}_{4}\right)_{2} \mathrm{O} \cdot \mathrm{P}_{2} \mathrm{O}_{5} \cdot 24 \mathrm{MoO}_{3}+2(22-x) \mathrm{NH}_{4} \mathrm{OH}=19\left(\mathrm{NH}_{4}\right)_{2} \mathrm{O} \cdot \mathrm{MoO}_{3}+ \\
3\left(\mathrm{NH}_{4}\right)_{2} \mathrm{O} \cdot \mathrm{P}_{2} \mathrm{O}_{5} \cdot 5 \mathrm{MoO}_{3}+(22-x) \mathrm{H}_{2} \mathrm{O} .
\end{gathered}
$$

This would serve as an explanation of the separation from the ammonia solution by Gibbs (loc. cit.), under certain conditions, of Debray's duodecaphosphomolybdate, since the pentaphosphomolybdate salts in certain circumstances split off phosphoric acid :

$$
4\left(5 \mathrm{MoO}_{3} \cdot \mathrm{P}_{2} \mathrm{O}_{5}\right)+9 \mathrm{H}_{2} \mathrm{O}=20 \mathrm{MoO}_{3} \cdot \mathrm{P}_{2} \mathrm{O}_{5}+6 \mathrm{H}_{3} \mathrm{PO}_{4} \text {. }
$$

It is difficult to see, therefore, how a satisfactory product for weighing can be obtained by heating the residue at $100^{\circ} \mathrm{C}$. or by partial ignition, since ammonium 
phosphate readily loses ammonia on heating, and the molybdate is partially reduced with the formation of blue molybdic oxide $\left(\mathrm{Mo}_{3} \mathrm{O}_{8}\right)$. There would also appear a possible danger, by overheating, of loss of phosphoric acid. By the ordinary method used in the analytical laboratories of the South-Eastern Agricultural College, the residue is heated over an Argand burner for some time, and weighed in a partially blue state. Taking at random the residue in five phosphoric acid estimations in soils, and further heating, till uniformly blue, over a medium-sized Bunsen flame, different percentage losses were obtained, although the blue residues after moderately strong heating for another half-hour in no case lost any further weight.

TABLE II.

\begin{tabular}{|c|c|c|c|c|c|}
\hline & Soil. & & $\begin{array}{l}\text { Weight of Residue } \\
\text { partially Blue. }\end{array}$ & $\begin{array}{l}\text { Weight of Residue } \\
\text { wholly Blue. }\end{array}$ & Loss on Heating. \\
\hline $\begin{array}{l}1 \\
2 \\
3 \\
4 \\
5\end{array}$ & $\begin{array}{l}\ldots \\
\cdots \\
. \\
\ldots \\
\ldots\end{array}$ & $\begin{array}{l}\ldots \\
\ldots \\
\cdots \\
\cdots \\
\ldots\end{array}$ & $\begin{array}{c}\text { Grms. } \\
0.0770 \\
0.1595 \\
0.0981 \\
0.1452 \\
0.0679\end{array}$ & $\begin{array}{c}\text { Grms. } \\
0.0710 \\
0.1535 \\
0.0909 \\
0.1390 \\
0.0650\end{array}$ & $\begin{array}{c}\text { Per Cent. } \\
7 \cdot 5 \\
3 \cdot 7 \\
7 \cdot 1 \\
4 \cdot 1 \\
4 \cdot 4\end{array}$ \\
\hline
\end{tabular}

The effect of heating until uniformly blue and of constant weight was consequently tried with precipitates dissolved in ammonia obtained from standard phosphate solutions, and also with soil extracts, in order to determine the constancy of the $\mathrm{P}_{2} \mathrm{O}_{5}$ content. The results are given in Tables III. and IV.

TABLE III.

Solutions of $\frac{N}{5}$ Sodium Phosphate.

\begin{tabular}{|c|c|c|c|c|c|}
\hline \multirow{2}{*}{$\begin{array}{l}\text { Weight of } \\
\mathrm{P}_{2} \mathrm{O}_{5} \text { taken. }\end{array}$} & \multicolumn{2}{|c|}{ Partially Blue Residue. } & \multirow{2}{*}{$\begin{array}{l}\text { Loss on } \\
\text { Ignition. }\end{array}$} & \multicolumn{2}{|c|}{ Blue Residue. } \\
\hline & Weight. & Factor. & & Weight. & Factor. \\
\hline $\begin{array}{c}\text { Grms. } \\
0.0946 \\
0.0473 \\
0.0460 \\
0.0236 \\
0.0710 \\
0.0710 \\
0.0946 \\
0.0946\end{array}$ & $\begin{array}{c}\text { Grms. } \\
1 . \overline{2800} \\
1.2153 \\
0.6650 \\
1.9271 \\
1.9280 \\
2.5002 \\
2.5256\end{array}$ & $\begin{array}{l}0 . \overline{0372} \\
0.0379 \\
0.0356 \\
0.0368 \\
0.0368 \\
0.0378 \\
0.0375\end{array}$ & $\begin{array}{c}\text { Per Cent. } \\
\begin{array}{l}\overline{4} \cdot 6 \\
\overline{3 \cdot 7} \\
4 \cdot 2 \\
5 \cdot 5 \\
4 \cdot 1 \\
4 \cdot 8\end{array}\end{array}$ & $\begin{array}{c}\text { Grms. } \\
2 \cdot 3995 \\
1 \cdot 2215 \\
- \\
0 \cdot 6111 \\
1 \cdot 8450 \\
1 \cdot 8221 \\
2 \cdot 3969 \\
2 \cdot 4050\end{array}$ & $\begin{array}{l}0.0394 \\
0.0388 \\
0.0387 \\
0.0385 \\
0.0385 \\
0.0389 \\
0.0394 \\
0.0393\end{array}$ \\
\hline
\end{tabular}


TABLE IV.

Soil Extracts.

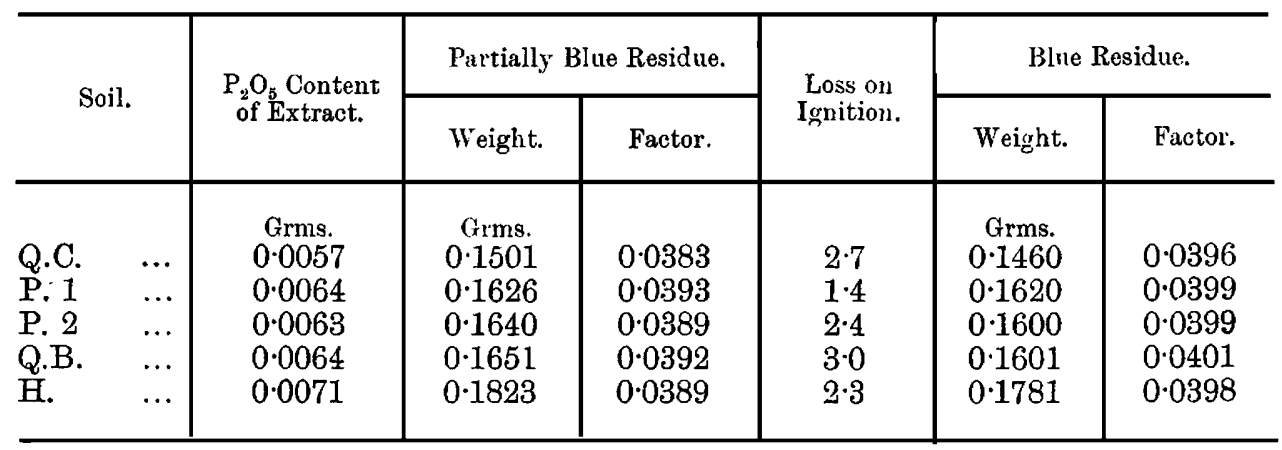

This series of soils was simply one of many tested during the ordinary routine analytical work, and the residues in Column 3 give the actual weights taken for calculation. The difficulty of testing the soil content sufficiently accurately by estimation as magnesium pyrophosphate may be responsible for the high factor obtained, but the experience gained in these numerous analyses rather points to a difficulty of preventing the decomposition of the yellow compound where the amount is small, and the gradual uttainment of a more uniform weight and factor on heating. From this point of view the figures in Tables III. and IV. are very suggestive, the rather bluer "yellow" residues from the smaller phosphoric acid content of the soils giving higher, but more concordant, factors than those from the yellower residues of Table III. It must be remembered, also, that the residues in Column 3 of Table IV. were obtained by Mr. R. H. Carter, the College analyst, in the ordinary course of practice, and in the case of the bigher factors for P. 1 and Q.B. the residues were much more blue than the others.

The experiments would therefore seem to show that residues containing, on the average, 3.891 per cent. of phosphoric acid are generally obtained by the method described by Hall, as against the 3.794 actually laid down. The factors obtained by heating the ammoniacal solution residues to complete blueness are more concordant than those obtained in practice from the yellow residues, and average 0.0393 ; but, in harmony with the non-uniformity of the residue, as shown above, the results vary somewhat.

Much better results were obtained by heating the yellow ammonium phosphomolybdate precipitate direct until it is of a blue colour. This method is described by Wood (loc. cit.). He gives the blue residue the same formula-viz., $\mathrm{P}_{2} \mathrm{O}_{5} \cdot 24 \mathrm{MoO}_{3}$ as that obtained by heating the residue after dissolution in ammonia, and uses the same coefficient for calculating the results-viz., 0.0396.

Owing to the necessity of freeing the yellow precipitate from silica or other contamination, the procedure described below was eventually adopted.

Method Recommended. - The yellow precipitate obtained in the ordinary way is dissolved in dilute ammonia, and the filtered solution reprecipitated by the addition of 
excess of nitric acid ( 1 part of acid to 2 parts of water). A further 5 c.c. of ammonium molybdate solution are also added, and the mixture is allowed to stand in a warm place for some time, as in the first precipitation. The precipitate thus obtained is of a fine consistency, and may be completely filtered with ease and rapidity through a Gooch crucible. It is then washed thoroughly with 1 per cent. nitric acid, dried in the oven, and ignited until of a uniform dark blue colour and of constant weight. During ignition the base of the Gooch should be protected by a cap or by placing it inside another crucible.

A quicker method, useful for students, and nearly as accurate, consists of reprecipitating the ammonia solution with nitric acid in a porcelain dish, washing out most of the ammonium nitrate by decantation, and, after drying on the waterbath, igniting until uniformly blue. Very little phosphoric acid remains in solution after addition of the nitric acid.

The results obtained by the method are given below :

TABLE V.

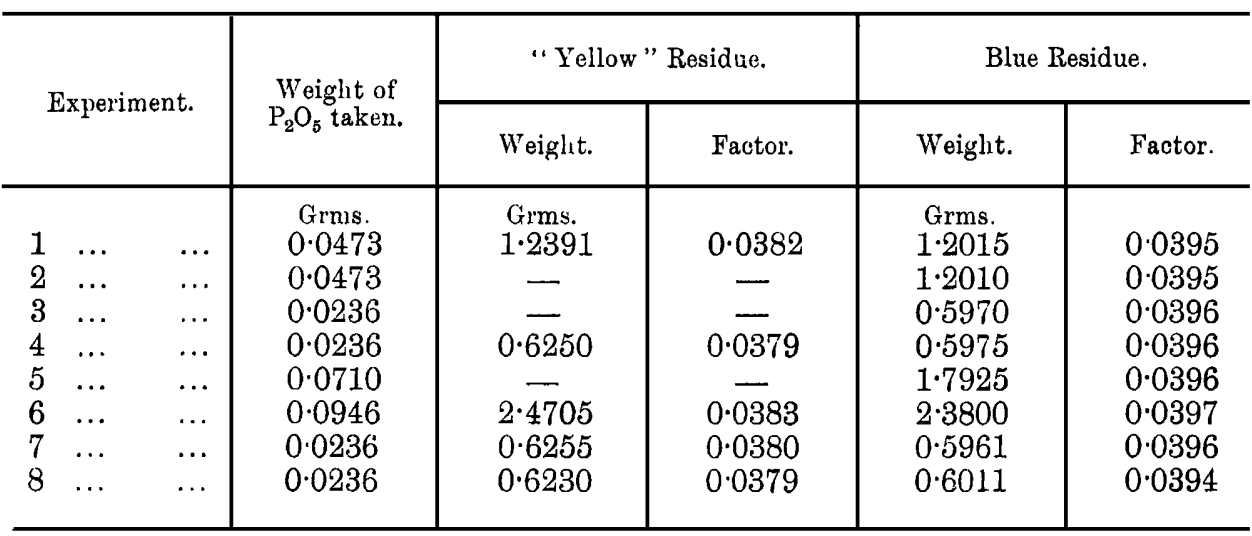

The factors from the yellow resides vary much as before, but by careful manipulation very constant results were obtained with the blue residues, the average being 0.0396 .

It is interesting to find that the coefficient obtained does not correspond to the phosphomolybdic acid $\left(\mathrm{P}_{2} \mathrm{O}_{5} \cdot 24 \mathrm{MoO}_{3}\right)$, which contains 3.94 per cent. of $\mathrm{P}_{2} \mathrm{O}_{5}$, but to a partial reduction corresponding to the formula $\mathrm{P}_{2} \mathrm{O}_{5} \cdot \mathrm{Mo}_{3} \mathrm{O}_{8} \cdot 21 \mathrm{MoO}_{3}$.

\section{Summary of Results.}

1. Owing to the difficulty of controlling the amount of ammonium salts present, and the possible variation of the amount of combined ammonia, methods of weighing the phosphomolybdate precipitate direct should be avoided. If used, Carnot's method should be employed, using the factor 0.0378 .

2. If the precipitate is dissolved in ammonia, the difficulty of removing ammonium salts without, in practice, decomposing the residue to an indefinite extent renders it desirable to weigh the residue in the uniformly blue condition. In 


\title{
136 PHOSPHOMOLYBDATE ESTIMATION OF PHOSPHORIC ACIDS IN SOILS
}

the ordinary method of heating till partially blue, the factor used should be 0.0389 ; if heated until quite blue, 0.0393 .

3. Since ammonia splits up the ordinary phosphomolybdate precipitate on solution, and the $\mathrm{P}_{2} \mathrm{O}_{5}$ content of the residue may be subject to variation, it is best to reprecipitate the ammoniacal solution with nitric acid, filter through a Gooch crucible, wash, and ignite the residue until dark blue in colour and of constant weight. Factor $=0.0396$.

4. As a quicker method of carrying out the operation, the reprecipitated phosphomolybdate may be washed by decantation, evaporated to dryness on the waterbath, and the residue ignited direct, using the same coefficient for calculating the result.

The author wishes to thank Mr. F. Knowles for carrying out some of the analyses quoted above.

\author{
Chemical Department, \\ South-Eastern Agricultural College, Wye.
}

\section{Discussion.}

Dr. Dyer said that ever since Hehner read his paper in 1879 , he had adopted Hehner's modification of the molybdic acid process for the determination of such small quantities of phosphoric acid as were contained in soil. If, after the ammoniacal solution was evaporated down, the residue was again evaporated two or three times with water, as Hehner had suggested, a precipitate was obtained which could be rapidly dried in the water-oven to a constant weight. If the evaporation with water were omitted, the residue had to be kept in the water-oven for a much longer time.

The President said that he used the molybdic acid method for the determination of phosphorus, chiefly in the case of steel and iron. The composition of the compound was perfectly definite, provided it was precipitated under definite conditions, which conditions, of course, must be duly learnt. Having obtained the precipitate under those definite conditions, he thought it immaterial by what method it was weighed. He had never found any difficulty in obtaining correct results by drying the precipitate in a porcelain crucible at $100^{\circ} \mathrm{C}$. in the water-oven, the precipitate being rinsed from the filterpaper into the crucible and dried and weighed. Latterly, however, he had adopted the more rapid method of Handy-namely, dissolving the precipitate from the filter with a standard solution of caustic soda and titrating back the excess of soda with standard nitric acid solution. When it was desired to check the results, a larger quantity of steel was taken, and the larger molybdate precipitate was redissolved, and the phosphorus precipitated with magnesia mixture and weighed as magnesium pyrophosphate. The results commonly agreed within a point or two in the third decimal place, which showed that the composition of the molybdate precipitate was quite definite, and also that its reaction with caustic soda was definite, so that probably its reaction with ammonia would be equally definite.

Dr. AULD, in reply, said that the estimation of phosphoric acid in soil called for a nearer approach to absolute accuracy than many other chemical estimations, 
because in the conversion of the results, say, into pounds per acre, any error that might exist was very largely multiplied. He therefore could not agree that it was not desirable to get as near to scientific exactitude as possible. It was only recently that his attention had been directed to Hehner's method, and he had never seen it used-perhaps because the washing of the precipitale with alcohol and its repeated evaporation with water were regarded as troublesome-and from that point of view it was an advantage to be able to weigh the precipitate at once without further manipulation. He agreed that the composition of the precipitate was, practically speaking, constant, but with very small quantities* the error due to the use of an inexact factor became relatively large. He had found titration to give good results, but in order to keep the experimental error of reading within proper limits about 12 c.c. of liquid must be used in an ordinary burette, and with soils the precipitate was usually too small to allow of this unless the quantity worked upon was inconveniently large.

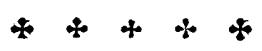

* Such as were obtained in estimating the "citric soluble" phosphoric acid in soil, and in which the weight of residue might not be more than $0.03 \mathrm{grm}$. 